\title{
Trainees' forum
}

\section{Junior psychiatrists and the "new deal"}

\author{
Simon SmITH, Registrar, Monyhull Hospital, Kings Norton, Birmingham B30 3QB; \\ SimoNe ENGLAND, Registrar, Queen Elizabeth Psychiatric Hospital; \\ MoNica DosHI, Registar, Queen Elizabeth Psychiatric Hospital, Edgbaston, \\ Birmingham B15 2QZ; and MARK WEAVER, Registrar, St Margaret's Hospital, \\ Great Barr, Birmingham B43 7EZ
}

The "new deal" for junior doctors is set to ensure reduction of hours worked to a maximum of 72 per week by the end of 1996 . To facilitate this reduction, juniors with a higher workload are being asked to consider alternative working patterns to the traditional "on-call" total system, and either work full shift systems (e.g. as in casualty departments) or a partial shift system that falls between these two extremes.

\section{The "new deal": is it relevant to psychiatrists?}

Should psychiatrists assume they can be excluded from review of working patterns necessitated by the "new deal"? While our own rotational training scheme, which incorporates 36 registrar posts in 11 hospitals around Birmingham, does include positions where the "on-call" workload is exceedingly quiet, other posts contravene the guidelines for rota patterns set by the "new deal". It is our perception that smaller, often district general hospital-based rotational schemes, have a much greater proportion of onerous posts. There appears to be a case for review of working patterns, if only in certain posts.

The regional task forces that have been set up to implement the "new deal" are presently concentrating on posts in the specialities of general medicine, surgery, paediatrics, and obstetrics and gynaecology. Junior doctors in psychiatry have had little contact with task forces. Other specialities perceive psychiatric posts to be free of problems related to hours or onerous duties, and likewise junior psychiatrists presently perceive their peers elsewhere to be significantly more hard pressed.

While appreciating that there are specialities which require a more urgent review of issues relating to hours than psychiatry, we must ensure that we do not, through preconception alone, omit this opportunity to review working patterns that in some posts may now be inappropriate.
Psychiatry is in the midst of change, particularly a shift to community based care. Consideration of such changes is vital to any review of working patterns. When community based, an on-call junior will be unable to walk down a hospital corridor to see a patient; rather a trip to casualty, police station or patient's home will result. In a geographically large catchment area, travelling time alone could turn a quiet post into an onerous one.

The dispersal of patients from hospital to community and the necessary medical cover they require may result in juniors being spread thinly or increasing the number of hours they work. Furthermore, attending to patients elsewhere than the confines of hospital can create a variety of difficulties increasing stress on the individual and the amount of time spent on any one task.

\section{Present work loads: are they arduous?}

To quantify work undertaken by junior psychiatrists out of hours, we asked colleagues at Hollymoor Hospital, Northfield, Birmingham to record the work done by themselves in their capacity as duty doctor. While this hospital was felt to be representative of hospitals on our rotation, it is worth stressing that it is a teaching hospital covering a densely populated urban area and thus is better provided with junior doctors than some units around the country. The hospital is a 227 -bed psychiatric unit offering a full district service. Juniors are on call one night in eight, a rota less arduous than many in smaller units.

We asked junior doctors on call for specific days to record the time spent in all out of hours tasks (between 5 p.m. and 9 a.m.). We also asked them to record the maximum number of hours of unbroken sleep achieved when on call. This record was undertaken during March 1992 and was completed for 30 of 31 possible days.

While the month was perceived as a quiet one, with $11.7 \%$ of "on-call" time between 5 p.m. and 9 a.m. 
spent working, our most relevant finding was that in 10 of 28 nights $(36 \%)$ where these data were recorded, less than eight hours unbroken sleep was obtained. On three nights $(10.7 \%)$ four or less hours were obtained. An average of 99 minutes a day (range: 2-250 minutes a day) was spent working between the hours of 5 p.m. to 11 p.m., and 30 minutes a day ( $0-140$ minutes) between 11 p.m. and 9 a.m.

Regional task forces set up to implement the "new deal" suggest that partial shifts may be used in hospitals where there is a less than $90 \%$ expectation of having less than eight hours unbroken sleep when on-call. This method of working could therefore be applicable to the hospital in question. There are, however, other pros and cons of different working patterns that need to be considered.

\section{Shifts: a change for the better?}

What advantages or disadvantages do the various systems of working offer to psychiatrists in training? On our rotational scheme there are no posts for which a full shift system would be suitable. This system is most useful where there is a small number of doctors covering a workload that is spread relatively evenly over 24 hours. While at present no such posts exist in Birmingham, we accept that other regions may have posts where this way of working might be considered, and indeed if workloads changed in our region we would consider the necessity of working in such a way.

Rota systems have the advantage of being familiar and allowing regular periods of free time. One is available in the day for one's patients and to attend courses or receive supervision from one's senior colleagues. This system becomes disadvantageous where days on call are so regular or onerous that doctors become chronically fatigued. Tired doctors are not only more likely to make errors of judgement, but will have reduced empathic qualities and be less able to benefit from educational opportunities.

In these situations a partial shift system might be appropriate. The type of partial shift could be adapted to the needs of the job ensuring that doctors are refreshed but that the majority of working time occurs between $9 \mathrm{a} . \mathrm{m}$. and $5 \mathrm{p} . \mathrm{m}$. when one can attend clinics, ward rounds, and lectures, and be available for one's patients during "sociable" hours.

\section{Conclusion}

When considering if one's post is hard pressed or not, and if other work patterns might suit one better, the nature of our work needs to be remembered, as do the possible changes to the way in which we work that will occur over the next few years. It is important to remain flexible in the face of these changes such that the way we work benefits patients and doctors alike. If junior psychiatrists choose to ignore potential changes for the better, posts will be left with inappropriate work patterns and this will be echoed by falling recruitment into the speciality. It is thus necessary for all trainees to view their work loads and decide if there could be a change for the better, and if so discuss this with consultants, managers and the regional task forces.

\section{Acknowledgements}

The authors would like to thank Drs J. Briscoe, $\mathbf{N}$. Coombes, S. Farooq, S. George, F. Roldan, S. Shortland-Webb, F. Souza-Faria and A. Taylor for their help in providing the data on out of hours work at Hollymoor Hospital. 